\title{
Narrativas militares actuales sobre la Guerra del Pacífico, 1879-1883
}

Narrativas militares atuais sobre a Guerra do Pacífico, 1879-1883

\section{Current Military Narratives on the War of the Pacific, 1879-1883}

Jerónimo Ríos'

DOI: 10.5752/P.2317-773X.2021v9.n1.p7

Recebido en 7 de diciembre de 2019

Acepto en 13 de abril de 2020

1. Investigador postdoctoral en la Facultad de Ciencias Políticas y Sociología de la Universidad Complutense de Madrid como beneficiario de las Ayudas de Atracción del Talento Investigador que cofinancia la Comunidad de Madrid (2018). Este trabajo es resultado del proyecto 2018-T2/SOC-10508. Email: jeronimo.rios@ucm.es ORCID: http:// orcid.org/0000-0003-3574-0116

\section{RESUMEN}

Este trabajo tiene como principal intención presentar narrativas y lecturas que, desde el alto estamento militar, se realizan actualmente en torno a la Guerra del Pacífico, acontecida entre 1879 y 1883 . El objetivo es mostrar de qué modo Generales y altos mandos militares de los tres países implicados en el conflicto bélico relatan los acontecimientos sucedidos. De esta manera, los orígenes de la guerra, la inserción en el relato nacional, la configuración de las relaciones geopolíticas o los horizontes futuros son objeto de reflexión y análisis. Lo anterior, para mostrar de qué modo la guerra más importante en la configuración geopolítica de América Latina sigue muy presente tanto en el relato historiográfico como en el relato nacional.

Palabras-clave: Guerra del Pacífico. Historia Militar. Narrativas. Discursos. Fuerzas Militares.

\section{RESUMO}

Este trabalho tem como principal intenção apresentar narrativas e leituras que, do alto escalão militar, são feitas atualmente em torno da Guerra do Pacífico, ocorrida entre 1879 e 1883 . O objetivo é mostrar como generais e altos oficiais militares dos três países envolvidos na guerra relacionam os eventos ocorridos. Assim, as origens da guerra, a inserção na história nacional, a configuração das relações geopolíticas ou os horizontes futuros são objeto de reflexão e análise. O acima, para mostrar como a guerra mais importante na configuração geopolítica da América Latina ainda está muito presente tanto na história historiográfica quanto na história nacional.

Palavras-chave: Guerra Do Pacífico. História Militar. Narrativas. Discursos. Forças Militares. 


\begin{abstract}
This work has as main intention to present narratives and readings that, from the high military establishment, exist at the moment around the War of the Pacific, happened between 1879 and 1883. The objective is to show how Generals and senior military officers of the three countries involved in the war relate the events of the war. Thus, elements such as the origins of the war, insertion in the national story, the configuration of geopolitical relations or the future of the region are analyzed. The above, to show how the most important war in the geopolitical configuration of Latin America is still very present both in the historiographic narrative and in the national story.
\end{abstract}

Keywords: War of the Pacific. Military History. Narratives. Discourses. Military Forces.

Introducción

El siguiente trabajo aborda las narrativas en torno a una guerra cuyas consecuencias siguen vigentes en el escenario latinoamericano: la Guerra del Pacífico. Una guerra que, entre 1879 y 1883, hunde sus raíces décadas atrás y proyecta sus consecuencias casi siglo y medio después. El objetivo general del trabajo es analizar las miradas que se realizan al respecto desde la historia militar de los tres países involucrados: Bolivia, Chile y Perú. Así, se trata de presentar cómo se comprende hoy el inicio de la guerra, sus motivaciones, su desarrollo y sus consecuencias. Esto, igualmente, para conocer cómo se inserta la guerra en el relato nacional, cómo se configura el espacio geopolítico y qué miradas ofrece para el futuro de la región.

Metodológicamente, el trabajo se sirve de relatos obtenidos a partir de entrevistas en profundidad con altos mandos de las Fuerzas Militares de Bolivia, Chile y Perú. Todos los entrevistados son historiadores militares -muchos de ellos, referencia académica en la disciplina latinoamericana- y algunos, con cargos de responsabilidad en los centros, comisiones y academias de la historia militar de sus respectivos países. De esta manera, permiten comprender de qué modo, aunque sus visiones no representan necesariamente la posición institucional de sus respectivos estamentos militares, entre historiadores militares de alto rango de los tres países involucrados, es posible encontrar lecturas en torno al hecho bélico claramente divergentes y enfrentadas entre sí.

Del lado boliviano fueron entrevistados tres reconocidos generales bolivianos como son Tomás Peña y Lillo (General de División (r) de las Fuerzas Armadas de Bolivia), Luis Fernando Alcázar (General de División (r) de las Fuerzas Armadas de Bolivia) y Víctor Manuel Jemio (General de División (r) de las Fuerzas Armadas de Bolivia). De lado chileno, cabe destacar la significativa participación de cuatro de las figuras de la historia militar más relevante del país: José Francisco Enberg Castro (Coronel (r) del Ejército chileno), Roberto Arancibia Claver (General de División del Ejército chileno), Christian Le Dantec (General de División (r) y ex Jefe del Estado Mayor Conjunto) y Marcos López Ardiles (General de División (r) del Ejército chileno y ex presidente de la Academia de Historia Militar). A todos ellos habría que añadir dos destacadas voces provenientes de 
Perú: Julio Cassaretto Bardales (Coronel (r) del Ejército del Perú) y Alberto Castro Villa (Mayor del Ejército Peruano y subdirector de la Comisión Permanente de Historia del Ejército del Perú). Todas las entrevistas se realizaron entre julio y septiembre de 2018.

Finalmente, el trabajo se estructura en cuatro partes claramente diferenciadas. En primer lugar, se presenta un breve marco teórico sobre lo importante del uso de las narrativas en la investigación geopolítica en la que se inscribe este trabajo. Después, se presentan algunas de las líneas predominantes en el análisis discursivo de la Guerra del Pacífico, lo cual, de alguna manera, hace parte de lo que se conoce como Historia Militar y en donde se podrá dar cuenta de una marcada impronta nacionalista (Black, 2004). En tercer lugar, y evitando una descripción de la Guerra del Pacífico - para lo cual ya existe una prolija literatura al respecto- se presentan las diferentes narrativas y comprensiones del hecho bélico objeto de estudio, a partir de miradas histórico-militares provenientes de Bolivia, Chile y Perú. Se concluye con las consideraciones más significativas planteadas, abriendo la vía a investigaciones futuras.

Las narrativas en la investigación histórica y geopolítica

El discurso geopolítico brinda la oportunidad de profundizar en el sentido de las prácticas políticas y las interpretaciones históricas y espaciales de la guerra. Así, es imprescindible abordar cómo las narrativas, entre otras cuestiones, configuras dichos discursos políticos. Tales narrativas, como proponen Ríos y Cairo (2018), han sido ampliamente utilizadas en la investigación social, política y geográfica. Por ejemplo, Prokkola (2014) y Kuus (2013) han hecho aportaciones al uso de las narrativas como método de investigación particular para la geografía política, dado que las narrativas permiten "darle sentido a la experiencia y construyen significado" (Prokkola, 2014: 442). Algo que permite ir más allá del estricto análisis semántico para entrar así en otros lugares de análisis como la enunciación o las estrategias de los actores emisores del discurso.

Entre las muchas formas de obtener narrativas sociales, este trabajo ha optado por dos de ellas: una revisión bibliográfica de artículos y trabajos, sobre todo de carácter discursivo y también historiográfico, y entrevistas semiestructuradas y en profundidad a personalidades de la historia militar de los países involucrados en la Guerra del Pacífico.

Aunque inicialmente pudiera reconocerse el hecho de que el uso de entrevistas en la investigación geopolítica es más infrecuente que en otros ámbitos, la misma Kuus (2017) reconoce que su utilidad sirve para superar las limitaciones de las investigaciones de "especialistas" que no pueden embarcarse en un trabajo etnográfico más amplio:

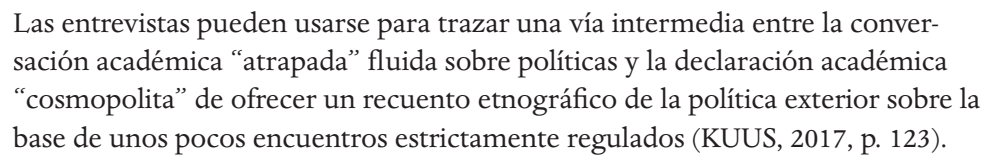

Si bien es cierto que Kuus orienta su trabajo a reflexionar sobre el uso de la etnografía en el análisis de las burocracias encargadas de la política exterior, su validez es extrapolable para un trabajo como éste, 
que explora la interpretación geopolítica de la Guerra del Pacífico, tanto en retrospectiva como mirando al futuro. Lo anterior, también, porque en entrevistas de una hora, "el investigador es alimentado con temas de discusión propios de un relaciones públicas" (2013: 118). Ello no sustituye al trabajo etnográfico, pero permite disponer de datos significativos para entender el alcance histórico-espacial de las narrativas de los entrevistados en torno a la guerra.

Las narrativas son parte del análisis del discurso y conducen a distintas argumentaciones desde las que comprender un fenómeno particular. Así, recurrir a las narrativas facilita la posibilidad de construir un conocimiento sistemático sobre el que se interpretan y representan procesos geopolíticos e históricos en donde cobran significado los relatos (Lanza, 2017), como en esta ocasión, de las Fuerzas Militares en torno a la Guerra del Pacífico. Esto supone atender y entender el modo en el que se proyectan las lecturas e interpretaciones actuales, tanto en clave geopolítica ad extra, como en relación con el mismo relato nacional, ad intra. Empero, no por ello las narrativas y relatos deben reducirse a dimensiones temporales restringidas, sino que los testimonios, como se plantean, han de responder a lecturas que se remonten a lo largo del tiempo. Esto, para que su confluencia favorezca la creación de una trama en la que se contrasta el objeto de análisis desde la interacción entre las conjeturas propias del investigador y la evidencia relativa del fenómeno estudiado (Barzelay y Cortázar, 2004).

Lo anterior, como proponen Ríos y Cairo (2018), no es óbice para que las narrativas estén cargadas de ideología, dada la propia dimensión política del objeto de estudio, y en tanto que son "mapas de una realidad social problemática y matrices para crear una conciencia colectiva" (Geertz, 1987: 178). Dicho de otro modo, las narrativas han de interpretarse cargadas de una ideología que define u oscurece categorías sociales, estabiliza o perturba expectativas, mantiene o mina normas, fortalece o debilita el consenso y alivia o exacerba las tensiones (Ariño, 1997; Van Dijk, 2005 en Ríos y Cairo, 2018).

Finalmente, todo lo expuesto se inscribe sobre la base de un marco conceptual y de categorías de análisis que se centrarán en visibilizar las lecturas que se hacen sobre 1) lo que supuso la Guerra del Pacífico en términos de configuración del código geopolítico de cada uno de los interesados; 2) las rupturas y/o continuidades, desde entonces, en las relaciones de los tres países involucrados; y 3) las percepciones, imaginarios, atributos o consideraciones que, mediatizados por el acontecimiento de la guerra, predominan entre los vecinos de la región, con base en un importante acervo nacional.

En conclusión, es en los conflictos del significado dónde verdaderamente tiene lugar la política y el sentido histórico (Edelman, 1991). En el lenguaje presente en las narrativas se podrá dar cuenta, como plantean Van Dijk (2004), de qué manera se constituye el significado aliado/enemigo, las fronteras de la relación conflicto/cooperación, los distintos niveles de legitimación de las relaciones geopolíticas herencia de la guerra, aparte de las lecturas reconstructivas del pasado y de las proyecciones hacia el futuro, en este caso, entre los protagonistas de la Guerra del Pacífico. 
Revisitando la literatura sobre la guerra del pacífico

De la Guerra del Pacífico se ha escrito una prolija literatura, siendo obligada referencia los trabajos de Sater (2007) o Farcau (2000), aparte de las aproximaciones particulares de Querejazu (1978), Abecía (1979) y Klein (1996) sobre Bolivia, de Blakemore (1986) Sater (1986) o Stockmeyer (2016) respecto de Chile, o de Bonilla (1974; 1980) y Klaren (1996) en torno a Perú. Recientemente, sobre Chile se ha investigado respecto de sus acciones de botines y saqueos (Olguín, 2016) o de la confiscación de bienes culturales limeños por las tropas chilenas (Godoy, 2011). Igualmente, existen trabajos centrados en las consecuencias de la guerra sobre los códigos geopolíticos de los países intervinientes, como el trabajo de Figueroa (2011) y las relaciones Chile-Ecuador. También, en los últimos años se han publicado investigaciones sobre las consecuencias de la guerra y la muerte entre soldados aliados de Bolivia y Perú durante la campaña de Tacna (Rojas, Araya y Ramírez, 2017); sobre la recuperación económica de los países perdedores (Zegarra, 2018) o respecto de los costes económicos de la guerra (Sicotte, Vizcarra y Wandsschneider, 2009). De igual modo, en referencia a las causas de la guerra, ya sea en atención a la cuestión salitrera (Mora, 2008; Godoy, 2016), o en relación a la construcción del espacio geopolítico en disputa, como sugieren Figueroa (2011), Miranda y Gómez (2016) o McEvoy (2006).

Desde la mirada de los estudios sobre la construcción y el significado de los discursos en los últimos años es posible encontrar una literatura abundante. Arellano (2015) intenta mostrar el modo en que se construyó el discurso chileno a tenor de la Guerra del Pacífico y cómo éste sirvió para estimular el acervo nacional y justificar la violencia sobre la agresión externa. Otros como Ibarra (2016) se centran en la sátira cómica y periodística sobre peruanos y bolivianos bajo los años de la guerra, mientras que Rojas y Salazar (2015) analizan la misma cuestión, pero desde la representación escénica y teatral. Aportaciones como la de McEvoy (2012) se focalizan en el trinomio discursivo chileno "masculinidad-superioridad racial-civilización" frente a los países aliados. Sobre Perú cabría destacar el aporte de González (2014), centrado en el fervor patriótico y en el racismo, mutuamente excluyente, y especialmente de peruanos y chilenos, como reconoce Arellano (2012).

Asimismo, McEvoy $(2010 ; 2011)$ se detiene en la clave identidad/alteridad y civilización/barbarie para entender los discursos de la Guerra del Pacífico. Finalmente, no se pueden pasar por alto otras aportaciones, centradas en la relación guerra/educación del trabajo de Fernández et al., (2017), que muestra cómo los relatos de la guerra son insertados en los materiales educativos de los países en disputa, produciéndose una recreación e interpretación de los acontecimientos bajo la mirada del orgullo nacional. Finalmente, en lo que concierne a los imaginarios enfrentados debe mencionarse el aporte de Parodi (2010), en relación a cómo os manuales chilenos representan la Guerra del Pacífico y, asimismo, cómo lo hacen los peruanos (Parodi y Chaupis, 2019). 
La Guerra del Pacífico: una mirada retrospectiva sobre sus orígenes

Un primer punto de confrontación discursiva gravita en torno al origen mismo de la guerra. Cuando se habla del inicio de la Guerra del Pacífico, predomina como desencadenante la subida de impuestos de febrero de 1878 a la Compañía de Salitres y Ferrocarril de Antofagasta, lo cual vulneraba a todas luces el tratado de 1874 . Frente a esta situación, Chile es que solicita un proceso de arbitraje que el entonces mandatario boliviano, Hilarión Daza, rechaza por entender que es un aspecto interno de la soberanía boliviana.
El no cumplimiento por parte de Bolivia de tratados contraídos entre ambos países (tratados de 1866 y 1874) marca el inicio de todo. Bolivia no aceptó un arbitraje solicitado por Chile, no quedando más remedio que ocupar Antofagas- ta para defender sus intereses económicos, que se consideraban vitales para el precario desarrollo en esa época (Entrevista al Coronel Francisco Enberg (Chile), julio de 2018).

A pesar de ser interpretado como una respuesta normal a la provocación boliviana, en la mirada del altiplano se plantea que la subida del impuesto y la vulneración del tratado de 1874 más bien fue un pretexto que fungió como casus belli de una tensión y una aspiración mucho más compleja y remota en el tiempo:

\footnotetext{
Se ha querido imponer algunos criterios que están basados en mentiras y falacias y que han configurado una historia que no responde a la verdad. Por ejemplo, la elevación de los impuestos o el incumplimiento del tratado de 1874, cuando fue fruto de una ambición anglo-chilena sobre el guano y salitre (Entrevista al General Alcázar (Bolivia), agosto de 2018).
}

Estas dos miradas distintas sobre el controvertido tema del impuesto conducen a un debate historiográfico más amplio, que pasa por identificar cuál es el verdadero punto de partida de la crisis que origina la Guerra del Pacífico. Lo anterior, añadido a la principal motivación geopolítica que reposa en la agresión chilena. Así, al remontarse a los orígenes de las tensiones territoriales entre Perú, Chile, Bolivia y Argentina, un punto de partida que dificulta todo lo anterior es la imprecisión de las fronteras de la herencia colonial, y que ya alimentó otras controversias en la segunda década del siglo XIX. También, el hecho de que Tarapacá y Antofagasta se descubriesen grandes cunas de salitre y guano va a alimentar discrepancias y reclamos, especialmente, entre Chile y Bolivia, de modo que, para la mirada boliviana, es ahí donde inicia la Guerra del Pacífico.

\footnotetext{
La invasión no empezó en febrero de 1879 como aparece en los anales, porque el 31 de octubre de 1842, Chile aprueba la Ley Rengifo donde se apoderaba de las guaneras de Atacama en el $23^{\circ} \mathrm{S}$. Ahí comienza el problema marítimo y su avance hacia al norte (Entrevista al General Alcázar (Bolivia), agosto de 2018).

Desde 1842, cuando se descubre la riqueza mineralógica de Bolivia, es que comienzan los intentos reiterados de usurpación por parte de Chile, quien se prepara para el despojo, el saqueo y la usurpación. Es decir, la guerra comenzó en 1842 y Chile se preparó durante 36 años) Entrevista al General Alcázar (Bolivia), agosto de 2018.
}

Después llegarán los tratados limítrofes de 1866 -por los que se establecía el límite sobre el paralelo $24^{\circ} \mathrm{S}$ y se compartían las ganancias de los minerales que se extraían entre el $23^{\circ} \mathrm{S}$ y el $25^{\circ} \mathrm{S}$. Este tratado sería anulado por el gobierno boliviano de Mariano Melgarejo, en 1871, firmándose un 
segundo tratado, en 1874, que fijaba la tasa impositiva sobre la extracción de salitre y guano -y que Hilarión Daza vulnerará en 1878 desencadenando la guerra. Tal y como cabe advertir, el recelo que Chile comienza a generar en la región es manifiesto y resulta extensible a vecinos como Argentina, Bolivia y Perú. Para la visión chilena, en cierto modo, pudiera pensarse que la guerra era una salida irrenunciable ante la falta de medios diplomáticos:

\begin{abstract}
La Guerra del Pacífico constituye la resolución de conflictos que se arrastraban desde la colonia entre naciones en proceso de consolidación que no pudieron ser solucionados por la política. En el caso de Chile - Bolivia es la consolidación de las fronteras y en el caso de Chile - Perú, la lucha de poder por la hegemonía económica en el Pacifico (Entrevista al General Le Dantec (Chile), julio de 2018).

Me impresiona la capacidad de respuesta que tuvo el Estado de Chile y sus ciudadanos frente a la provocación del gobierno boliviano, que transgredió un tratado internacional firmado en 1874. La reacción gradual que observó Chile ante la decisión del gobierno de La Paz de cobrar impuestos a las empresas chilenas y, más tarde, de proceder a su remate, es una demostración de que el gobierno de Chile buscó diversos caminos diplomáticos antes de emplear la fuerza para reivindicar sus derechos (Entrevista al General López (Chile), julio de 2018).
\end{abstract}

Lo anterior justificaría el controvertido acuerdo secreto - no tan secreto- entre Bolivia y Perú, suscrito en 1873, y que implicaba una asistencia militar recíproca con la vista puesta en el inminente y previsto expansionismo territorial chileno, para lo cual también se invitó a Argentina, que mantenía, sin embargo, controversias irresolutas con Bolivia, por la zona de Tarija. Para el discurso chileno éste es otro de los elementos que desencadenó la guerra:

\begin{abstract}
La Guerra del Pacífico supone un enorme esfuerzo que hizo Chile entero para defender lo que consideraba sus derechos al no cumplirse el Tratado de 1874 con Bolivia. Supone también que la participación del Perú se debió a su compromiso con Bolivia por el tratado secreto de 1873 y también a su agresiva campaña por el salitre (Entrevista al General Arancibia (Chile), julio de 2018).

La Guerra del Pacífico supone la acción mancomunada de dos naciones que habían suscrito en 1873 un pacto secreto de alianza militar, que no podía estar dirigido sino contra Chile. Tal fue el grado de animosidad que estos dos vecinos tenían contra Chile que seis años antes de la guerra, ya se habían coaligado en su contra (Entrevista al General López (Chile), julio de 2018).
\end{abstract}

Esta casus belli, que desde Chile justificaría una suerte de realismo preventivo ante lo inminente de la amenaza chileno/boliviana, hace que la lectura que plantean Bolivia y Perú resulte totalmente distinta. Desde la academia militar boliviana se reconoce que el acuerdo secreto no era tan secreto, y que la principal rivalidad no era tanto con Bolivia y sí más con Perú.

Perú se da cuenta de todo ello y de que el problema de fondo es que Chile busca la supremacía en el Pacífico sur. Es lo que mueve la firma del tratado defensivo, del cual Chile tenía pleno conocimiento porque los argentinos se lo habían dicho (Entrevista al General Peña y Lillo (Bolivia), agosto de 2018).

Los bolivianos entendemos que la Guerra del Pacífico fue toda una guerra de invasión, más contra Perú que contra Bolivia, si bien, por el tratado de asistencia recíproca que teníamos firmado con Perú fue que fuimos a la guerra (Entrevista al General Jemio (Bolivia), agosto de 2018).

Asimismo, para la posición peruana:

La Guerra del Pacífico se debe a una geopolítica netamente expansionista pues Chile necesitaba los recursos. Pero esto no se puede confundir con el hecho 
de que en Chile el expansionismo fuese súbito. Hay un punto de quiebre en la guerra hispanoamericana de 1864-1866, cuando para defenderse de los españoles recurren a pedir ayuda a Perú y a su flota naval, que en ese momento era mayor, y que supone, en cierto modo, un trauma para Chile (Entrevista al Mayor Castro (Perú), septiembre de 2018).

La evolución de la Guerra del Pacífico

Existe un mayor consenso entre los historiadores militares bolivianos, chilenos y peruanos sobre el desarrollo de la guerra y las consecuencias, aún presentes, que ésta dejó en el litoral del Pacífico latinoamericano. Hay un mutuo convencimiento de que la carrera militar armamentista que venía desarrollando Chile desde hacía años le confería una posición de ventaja sobre la alianza boliviano-peruana:

Las Fuerzas Armadas de Chile eran más fuertes y preparadas. Ellos ya venían del conflicto de 1876 con Argentina por la Patagonia y para 1879 tenían una Armada sin parangón y un Ejército muy bien equipado. Éramos un Estado sin Estado, sin institucionalidad, sin inclusión de la masa indígena. Éramos un Estado reventado por su economía (Entrevista al Coronel Cassaretto (Perú), septiembre de 2018).

Chile tenía una economía mucho más estable y una clase media más grande. Perú era todo lo contrario. Muy fracturado. Con una complicadísima geografía y sin estructura. Y lo mismo pasaba en Bolivia (Entrevista al Mayor Castro (Perú), septiembre de 2018)

Bolivia y Perú apenas se defienden por no darse cuenta, en ningún momento, del avance tecnológico que supone el cañón de retrocarga y el fusil de repetición. Esa superioridad tecnológica tan importante es la que resuelve la guerra y permite a un país depredar la zona en disputa (Entrevista al General Peña y Lillo (Bolivia), agosto de 2018).

Este discurso contrastaría con el discurso chileno, centrado en ensalzar la causa nacional de un pueblo levantado en armas y que fue lo que le permitió salir victorioso de la guerra contra Perú y contra Bolivia:

\footnotetext{
La Guerra del Pacífico sería para Chile un esfuerzo extraordinario que comprometió a toda la nación y que, a pesar de encontrarse inicialmente en desigualdad de condiciones en cuanto a poder económico y militar, fue capaz de movilizar un ejército expedicionario que aumentaría su fuerza inicial de 2.400 hombres a una dotación de 25.000 soldados equipados y entrenados. (Entrevista al Coronel Enberg (Chile), julio de 2018).

La Guerra del Pacífico deja de manifiesto la superior capacidad de reacción militar de Chile, país que, con un Ejército inicial que no superaba los 2.500 hombres, logra movilizar a más de 60.000 ciudadanos a lo largo de los seis años de guerra. (Entrevista al General López (Chile), julio de 2018).
}

Finalmente, en el imaginario colectivo de la guerra se plantea que, en la evolución de la misma, un elemento siempre recurrido es la fractura de la relación boliviano-peruana, la cual se entiende bajo consideraciones de muy diferente signo. En el caso boliviano se reclama la lealtad a Perú, de manera que la salida de la guerra se debía, especialmente, a la incapacidad de sostener la misma a tenor de la situación interna atravesada por el país:

Con Perú se ha creado una leyenda negra en torno a que les hemos abandonado y consideran que la causa de la guerra fue la toma de Antofagasta y la agresión chilena a Bolivia. En su historia hemos pasado a ser los traidores a pesar de que hasta en 14 ocasiones hemos desestimado una agresión contra ellos y en favor de Chile, como también se llegó a plantear en la Guerra del Pacífico. Solo muy pocos reconocen el apoyo de sangre que les dimos (Entrevista al General Jemio (Bolivia), agosto de 2018). 
Algo que, con relativo escepticismo se interpretaría desde la mirada peruana y, especialmente, desde la mirada chilena, en donde predomina que la noción de que guerra tenía sentido más con Bolivia que con Perú.

Como Bolivia, teníamos problemas políticos y falta de unidad, pero de lo más importante es el abandono prematuro de la guerra por parte de Bolivia (Entrevista al Coronel Cassaretto (Perú), septiembre de 2018).

Chile se vio enfrentado también a Perú, país con el cual Chile no presentaba problemas. Inicialmente, Chile nunca pensó en ir a invadir la propia capital del Perú, esta alianza le costó al Perú casi cuatro años de ocupación militar en el corazón de su territorio, mientras que Bolivia, tras la derrota de las fuerzas aliadas peruano - bolivianas en la batalla de Tacna (26 de mayo de 1880), se retiraría del escenario de la guerra y abandonaría a su aliado a su suerte (Entrevista al Coronel Enberg (Chile), julio de 2018).

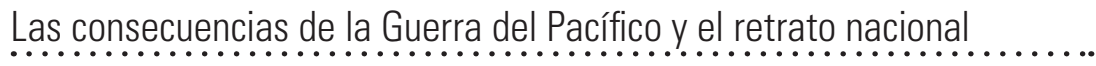

Las consecuencias de la Guerra del Pacífico distaron mucho en su alcance y significado para los tres países, pues si en Perú se alienta a la creación del sentimiento nacional, en Bolivia se alega al sentimiento de traición y agresión de parte de Chile. En ambos casos se observa un elemento configurador del relato patriótico y una lectura interpretativa de la relación nosotros/ellos con los vecinos regionales:

Es un antes y un después. Es lo que nos obliga a despertar de un caos como Estado. Es un hito. Es una herida vigente. Nuestros dos grandes hombres de la patria son Grau y Bolognesi. Mucho más allá de nuestros libertadores, la Guerra del Pacífico nos marcó como nación (Entrevista al Coronel Cassaretto (Perú), septiembre de 2018).

La Guerra del Pacífico es la guerra que nos otorga como nación a los hombres que han simbolizado los paradigmas nacionales, porque de la guerra independentista no tenemos imágenes o personajes que simbolicen el prohombre que toda nación necesita. La Guerra del Pacífico sirvió para fundar nuestra identidad nacional. Por eso encuentras por todas partes a Grau, Cáceres, Bolognesi (Entrevista al Mayor Castro (Perú), julio de 2018).

Como se señalaba, esta visión particular de la Guerra del Pacífico se alimenta, desde Bolivia, en términos de traición, usurpación o despojo, lo cual mostraría un nivel de aversión y de emocionalidad de una derrota hoy muy presente en el relato histórico-militar boliviano. Algo de lo que dan buena cuenta los tres generales e historiadores militares entrevistados:

En Bolivia hemos tenido guerras con los cinco vecinos: Brasil, Perú, Paraguay y Argentina. Hemos superado todas. Hemos cerrado las heridas, pero con Chile siguen abiertas por la Guerra del Pacífico. Con Chile lo que hay es rencor. Nos dio una puñalada por la espalda y de una forma abusiva (Entrevista al General Peña y Lillo (Bolivia), agosto de 2018).

Para el consciente colectivo de la bolivianidad, Chile es sinónimo de problema marítimo y la convivencia pacífica solo puede ser con eso. El ciudadano boliviano nace con un resentimiento hacia Chile donde se forma una verdad histórica, hay una daga en la espalda por la injusticia, la soberbia chilena y por los costos que eso implica (Entrevista al General Alcázar (Bolivia), agosto de 2018).

Finalmente, para Chile la Guerra del Pacífico deja consigo una afectación a las relaciones geopolíticas con los vecinos de la región pues:

Sus consecuencias exacerban sentimientos en la relación de poder en la región, estando siempre presentes en la relación entre estos Estados. Una inadecuada delimitación fronteriza al término del mismo y el hecho que los acuerdos se 
firmaran con gobiernos débiles y poco representativos, arrastran sentimientos reivindicatorios hasta nuestros días (Entrevista al General Le Dantec (Chile), julio de 2018).

La controvertida afirmación de quien fuera Jefe del Estado Mayor Conjunto de Chile, admitiría matices en las relaciones entre Chile y Bolivia y Chile y Perú. Una doble relación con una comprensión, interiorización y normalización de las consecuencias de la Guerra del Pacífico que pone de manifiesto diferentes miradas entre los involucrados. De esta manera, para el lado peruano se aprecia menos beligerancia con respecto a Chile, si bien se reconoce la vigencia de la enemistad en el imaginario colectivo:

La Guerra del Pacífico no afecta hoy en día a las relaciones gubernamentales. La Guerra del Pacífico es una espina, pero ya ha sido superada. Sin embargo, en el colectivo peruano sí que está presente en nuestros colegios, en nuestras plazas, en nuestro subconsciente. Hablamos de hermandad, pero la Guerra del Pacífico sigue y seguirá en todos nosotros (Entrevista al Coronel Cassaretto (Perú), septiembre de 2018).

Si los chilenos hubieran accedido a entregar esos tres kilómetros en el sur, eso hubiera sido una muestra de cerrar el tema y para los peruanos, en su imaginario colectivo, psicológico y mental, hubiera sido una victoria desde la que cerrar definidamente la cuestión. En Chile, junto a esta terquedad persisten relatos revisionistas y declaraciones hirientes que buscan que Perú 'pise el palito' (Entrevista al Mayor Castro (Perú), septiembre de 2018).

La mirada de escepticismo, en el caso de Bolivia, va más allá, admitiendo un tinte mucho más crítico, erigido desde la desconfianza y la percepción de Chile como un país beligerante y desestabilizador de la región.
Los chilenos tienen hipótesis para una guerra con los tres países al tiempo y es por eso que invierte continuamente en armamento. Chile es un país peligroso, muy militarizado y en condiciones de preparar una guerra entre los tres vecinos: todo, como resultado de la Guerra del Pacífico (Entrevista al General Peña y Lillo (Bolivia), agosto de 2018).
Nadie quiere enemistarse con Chile y nuestro derecho es muy urticante para los vecinos, incluido Chile, por ser una mancha en sus credenciales intachables de buenos vecinos que no son tan reales (Entrevista al General Jemio (Bolivia), agosto de 2018).

Del lado chileno, se reconocería una posición de rivalidad con ambos países si bien, como perfectamente recoge el testimonio del Coronel Enberg, con dos alcances y significaciones particulares:

Con Perú las relaciones diplomáticas se han mantenido en un estado de "normalidad", con los vaivenes propios de una diplomacia respetuosa. Pero aún está pendiente para Perú una cuestión de un pequeño triángulo terrestre producto de la proyección del hito $\mathrm{N}^{\circ} 1$ a un "Punto Concordia" o "Punto 266" reclamado por Perú, cosa que Chile se opone. Con Bolivia la situación es más compleja ya que no existen relaciones diplomáticas, y la cuestión de una salida al mar "con soberanía" por parte de Bolivia, constituye para ellos un objetivo nacional permanente. De acuerdo al tratado de 1904, prestamos servicios portuarios en Arica y Antofagasta a los productos que importa e exporta Bolivia, con un costo para Chile de cien millones de dólares anuales (Entrevista al Coronel Enberg (Chile), julio de 2018).

La cuestión marítima de la Guerra del Pacífico

Una de las cuestiones más espinosas que sigue afectando a las relaciones geopolíticas de América Latina tiene que ver con este reparto de tierras resultado de la Guerra del Pacífico. El Tratado de Ancón suscrito 
entre Chile y Perú dejaba como consecuencia más relevante que la región de Tarapacá pasaba a manos chilenas, además de ocuparse las provincias de Arica y Tacna por diez años, hasta que se fijara un plebiscito que resolviera si definitivamente quedaban en manos chilenas o peruanos. Lo mismo, con Bolivia, se firmaría el Pacto de Tregua, el 4 de abril de 1884, dejando consigo la ocupación chilena de Antofagasta y cercenando cualquier salida al Pacífico para Bolivia. Nuevamente, las lecturas son muy divergentes, especialmente, entre la mirada chilena y la boliviana:
Tenemos a Perú que ha aceptado la derrota y ha tomado nota, pero siempre está de guardia con Chile. Ellos no olvidan nada. Si Chile compra un avión, ellos compran otro. Si Chile compra barcos, Perú compra barcos. Hay una guardia permanente. Las ofensas nunca se olvidan. Bolivia tiene problemas mayores, al haberse cercenado su salida al mar. No tenemos fuerza militar en este momento para retornar al Pacífico, pero le digo que lograremos nuestro cometido por cualquiera de las formas que nos muestra la Historia (Entrevista al General Peña y Lillo (Bolivia), agosto de 2018).
El problema marítimo es un obstáculo muy serio para la integración regional porque Bolivia respira la necesidad de salida al mar y dejar atrás el enclaustra- miento injusto. Esto afecta comercialmente, representando el 1.5\% del PIB anual de Bolivia. ¿Cómo es posible que un país que tiene $6.000 \mathrm{~km}$ de costa y que ha vivido de la economía boliviana se niegue a la convivencia de ceder una salida soberana a Bolivia que no lo afectaría en nada? (Entrevista al General Alcázar (Bolivia), agosto de 2018).

Desde Perú se pudiera reconocer una aprobación a la reivindicación marítima de Bolivia, aunque se interpreta con relativa desconfianza, como reconoce el coronel peruano Julio Cassaretto, al afirmar que "Bolivia tiene un tratado de por medio y una reclamación que debiera ser concedida pero que difícilmente tiene salida. No hay forma que pueda recuperar nada, aunque lo justo fuese que lo hiciera". Asimismo, se entiende que la actual reivindicación marítima y territorial, boliviana y peruana, sirve para alimentar fervores patrióticos:

Lo de Bolivia no tiene comparación. Esto sirve para una perfecta utilización política por parte de muchos sectores nacionalistas de Perú y Bolivia, que utilizan al enemigo común chileno en lo que se denomina como la alteridad. Para nosotros más que la guerra en sí, lo más duro fue la posesión de Tacna nuevamente, que fueron más de cincuenta años (Entrevista al Mayor Castro (Perú), septiembre de 2018).

Nada que ver, ni una ni otra visión, con la mirada chilena, la cual queda perfectamente recogida en la siguiente reflexión del General chileno Le Dantec:

\begin{abstract}
La Guerra del Pacífico a afectado las relaciones geopolíticas hasta el día de hoy, han pasado 138 años y aún Perú y Bolivia no han podido cerrar sus heridas. Perú hasta el año 1979 pensaba todavía en la posibilidad de recuperar las "provincias cautivas" como ellos llaman a Tacna y Arica - cabe recordar que Tacna fue devuelto al Perú en 1929 - y para qué decir de Bolivia, que en la actualidad está en curso una demanda en la Corte Internacional de la Haya, en la que Bolivia demanda a Chile la obligación de "negociar una salida soberana al mar". Cosa que queda fuera de cualquier reclamo jurídico, ya que no se puede cambiar sin la anuencia de ambos países el límite político fijado en el tratado de Tratado de Paz de 1904, tratado que rige en la actualidad y que Chile obviamente no está dispuesto a negociar (Entrevista al General Le Dante (Chile), julio de 2018).
\end{abstract}

En todo caso, Bolivia es conocedora que sus aspiraciones, dadas las dificultades expuestas, pasan por una solución "a tres bandas", integrando a Perú en la solución: 
2. El Tratado de 1929 serviría para poner fin a la disputa chileno-peruana por las provincias de Tacna y Arica, la primera para Perú, la segunda para

Chile.
Solo muy pocos en Perú reconocen el apoyo de sangre que les dimos. Lo cierto, como se observa en el tratado de $1929^{2}$, es que hay mucho distanciamiento, pues también es que Chile tiene el candado y Perú la llave (Entrevista al General Jemio (Bolivia), agosto de 2018).

Perú se solidariza con el problema marítimo, pero Atacama para Bolivia es Arica para el Perú. Arica es para Perú su provincia cautiva. Esto configura el escenario porque obliga a tomar en cuenta la opinión de Perú de modo que el escenario debe ser tripartito. La negociación ha de ser tripartita para no despertar susceptibilidad, y antagonismos y sea participativa con un resultado de tres países que han de resultar ganadores en la solución (Entrevista al General Alcázar (Bolivia), agosto de 2018).

Mapa 1. Fronteras después de la Guerra del Pacífico, a partir del Tratado de 1929

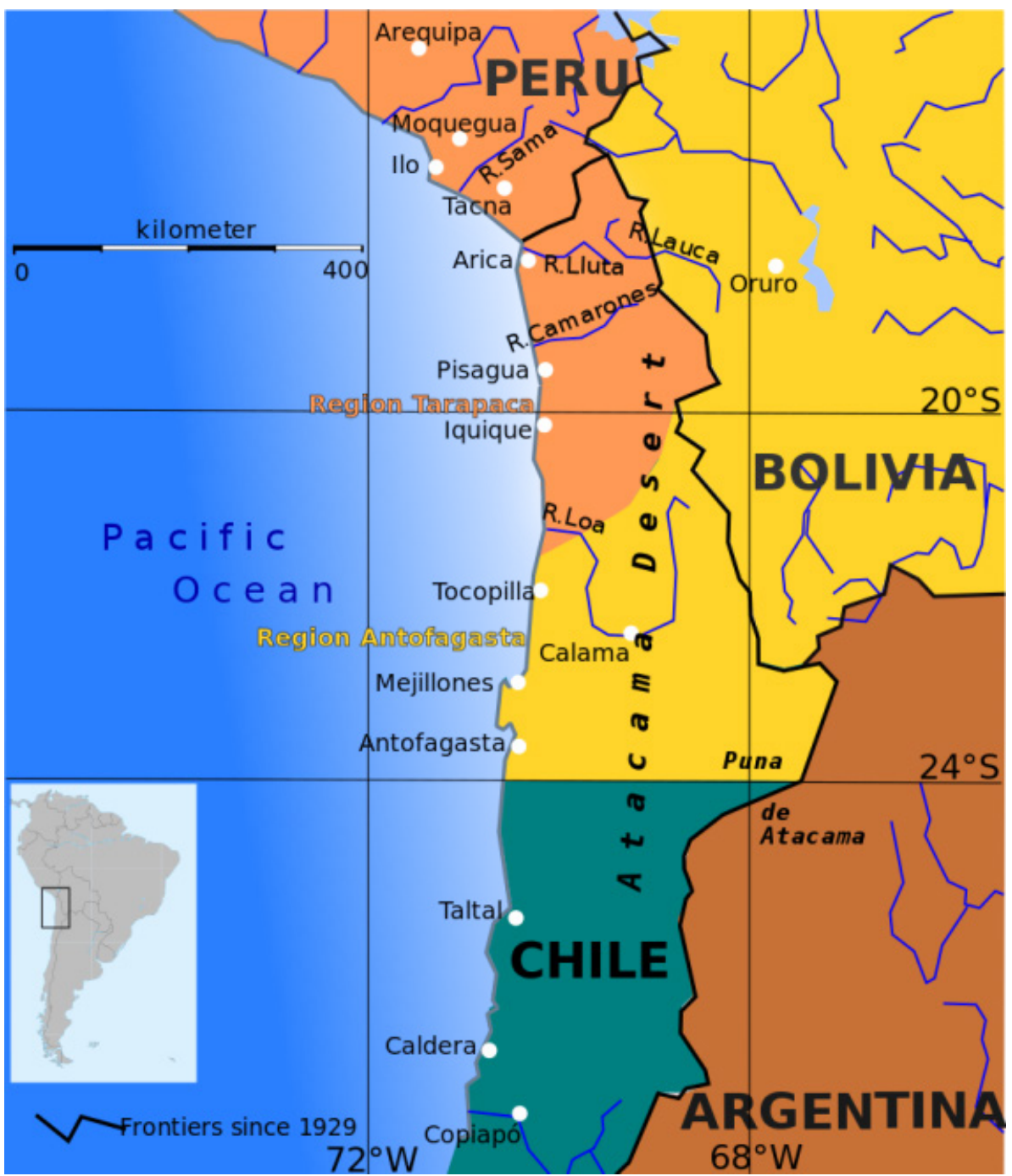

Fuente: Commons.

Una solución negociada e integradora

Cualquier salida de Bolivia al litoral Pacífico heredera directa de la Guerra del Pacífico, más allá de deseos ilusorios, pasa por concesiones que Chile pareciera no estar dispuesto a permitir y, además, por una solución tripartita que integre a Perú en la misma. Resultan más que evidentes los 
continuos llamados a negociar e integrar una solución por parte de todos los entrevistados cuando son preguntados por el escenario futuro de vecindad entre Chile, Bolivia y Perú. En todo caso las miradas bolivianas al respecto consideran que una victoria jurisdiccional ante La Haya -la cual finalmente no se produjo a tenor del fallo del 1 de octubre de 2018- no se traduciría en un acceso inmediato al litoral Pacífico:

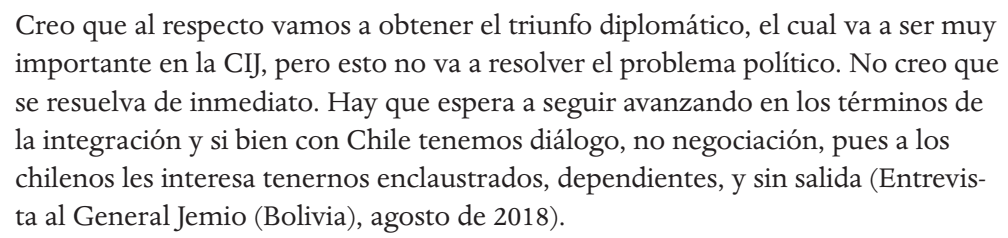

Lo mismo es lo que considera el General Alcázar, enfático en la necesidad de intercambios cooperativos y mayores esfuerzos del lado chileno:

\begin{abstract}
La primera responsabilidad es de parte de Chile. Deben asumir responsabilidades en el marco con su propia población con explicar la verdad histórica. No es que Bolivia nunca tuvo mar, como la tesis de 1956. Los propios historiadores chilenos han aclarado esto y por aquí va una primera responsabilidad que enfrenta la responsabilidad histórica. Una segunda responsabilidad es que debe hacer conciencia sobre las 69 oportunidades en las que Chile y Bolivia pudieron solucionar el problema negociado, 20 antes de 1904 y 49 después. A partir de esa realidad no podemos olvidar que somos tres países condenados a convivir y desarrollarnos juntos (Entrevista al General Alcázar (Bolivia), agosto de 2018).
\end{abstract}

Todo lo anterior, como es de esperar, colisiona con las miradas de Chile, centrada en los tratados de 1904 y 1929, y que son la razón de peso, por su vigencia, para negar cualquier atisbo de reclamación territorial en línea con el último fallo de la CIJ. Así, para uno de los más reconocidos historiadores militares chilenos, como es el General Arancibia, el problema es que Perú y Bolivia siguen mirando atrás:

\footnotetext{
El ideal sería seguir avanzando hacia el futuro unidos y dejar la guerra atrás, pero la concurrencia a La Haya de los tres países confirma que hay problemas que impiden marchar más veloces al futuro, y un ejemplo es el tema de la negociación que exige Bolivia por su salida al mar y la controversia del río Silala, y con Perú el tema que quedó pendiente que es su posición con respecto al triángulo terrestre en su frontera sur con Chile (Entrevista al General Arancibia (Chile), julio de 2018).
}

Otro general chileno como es Le Dantec considera la necesidad de inscribir el conflicto en la complejidad misma de la derrota que, sin fundamento, alimenta la posición beligerante de Perú y Bolivia en la región:

\footnotetext{
Perú y Bolivia, se consideraban superiores a los habitantes del sur que producto de los constantes conflictos con los pueblos originarios, fueron forjando una raza mucho más ruda, belicosa y esforzada con la cual debieron enfrentarse, por lo que predomina un sentimiento de débil a poderoso, donde perciben el conflicto como una agresión usurpadora de un vecino más fuerte creando y manteniendo en el tiempo efectos reivindicatorios (Entrevista al General Le Dantec (Chile), julio de 2018).
}

Finalmente, el General López, expresidente de la Academia de Historia Militar, idénticamente interpreta que se trata de una cuestión anacrónica, del pasado, y que solo se supera mirando al futuro:

El sólo hecho de que el Estado de Chile haya sido sujeto de demandas por parte del Perú y de Bolivia ante la CIJ, es una muestra de que la convivencia no consigue alcanzar los niveles de buena vecindad que requieren nuestras naciones. Las dos demandas han sido motivadas por asuntos que tiene su origen en la Guerra 
del Pacífico. Si se superaran los recelos y los revanchismos, los tres Estados que estuvieron en guerra hace más de 130 años, podrían incrementar mucho más sus lazos comerciales, explorando la complementariedad de sus economías (Entrevista al General López (Chile), julio de 2018).

La Guerra del Pacífico y el imaginario colectivo

El relato nacional se construye sobre la base de las guerras, victoriosas o derrotas, que confieren los nombres, los hitos y las fechas que, en el imaginario colectivo, se inscriben como los momentos forjadores de la nación. Ya se advertía cómo, para el caso de Perú, los entrevistados destacaban incluso a Grau, Cáceres o Bolognesi como los padres de la patria que no tuvieron tras la guerra independentista. De igual modo, cabría esperar un muy diferente relato de la Guerra del Pacífico respecto de cómo lo hacen Bolivia o Perú a cómo lo hace Chile. Así, del caso boliviano se destaca el papel significativo y la visceralidad que ya está presente desde la escuela y la infancia:

\begin{abstract}
Desde niños se nos enseña que fuimos víctimas de una agresión. Tenemos que defender Bolivia como sea. El servicio militar obligatorio, por ejemplo, cuando alguien llega con la idea de suprimirlo, automáticamente es acusado de ser chileno. Es resquemor es sobre lo que pasó y lo que debe pasar. Queremos salinas soberanas y salida al mar. Esto nunca se olvida y se transmite de generación en generación (Entrevista al General Peña y Lillo (Bolivia).

La Guerra del Pacífico está cargada de odio y rechazo a los chilenos. Nuestras escuelas, nuestros niños, desde pequeños, saben del expolio y del saqueo cometido por los chilenos. Eso no va a cambiar. Somos una historia de resentimiento contra los chilenos. El cobre, el guano, el salitre, el litio. Todo era de nuestro territorio (Entrevista al General Jemio (Bolivia), agosto de 2018).
\end{abstract}

Si bien la posición peruana era mostrada con anterioridad, el Coronel Cassaretto también resalta la importancia de la guerra en las escuelas peruanas, aunque de manera más matizada:

En nuestras escuelas miramos con profundidad lo sucedido. Más que en cualquier otra parte de América Latina. Se paran las clases con las fiestas de la guerra, incluso, con motivo del 5 de abril (Entrevista al Coronel Cassaretto (Perú), septiembre de 2018).

Todo lo anterior, lejos de la forma en la que se inserta la Guerra del Pacífico en el relato nacional chileno, como resalta el Coronel Enberg:

Mientras en Perú y Bolivia se continúa enseñando en los colegios una historia cargada de mitos y heroísmo exaltado, donde se muestra al soldado chileno que combatió en esa guerra como un verdadero demonio, en Chile el sentimiento de orgullo por haber ganado el conflicto se ha ido diluyendo en el tiempo. En Chile me atrevo a decir que cada vez menos se enseña esta guerra a los jóvenes y niños (Entrevista al Coronel Enberg (Chile), julio de 2018).

Conclusiones

Es posible advertir diferentes conclusiones con respecto a cómo hoy persiste en el imaginario colectivo de las Fuerzas Militares y sus historiadores, la Guerra del Pacífico. En primer lugar, se puede observar de qué modo esta guerra admite diferentes interpretaciones en cuanto a su origen, sus causas, su misma evolución y las consecuencias que dejó, mayormente, para Bolivia y Chile. 
También se da puede dar perfecta cuenta de cómo su vigencia afecta a las relaciones entre Chile y Bolivia, y cómo la disputa territorial marítima entre ambos y una pequeña reivindicación irresoluta en el sur peruano, hacen que no se haya cerrado el capítulo de la guerra, un siglo y medio después. Esto, nada baladí, no solo construye los imaginarios colectivos y transforma las alteridades de los vecinos del flanco sur latinoamericano. Además, permite exaltar nacionalismos y evocar acontecimientos que configuran el modo en el que son percibidos los respectivos vecinos de la región.

Llama poderosamente la atención que no haya ni siquiera acuerdos sobre el origen. Mientras que Bolivia y Perú hacen una lectura mucho más alejada a febrero de 1879 e inscriben en la década de los cuarenta el inicio de la guerra, en Chile reducen la lectura a los hechos derivados por la variación de precios sobre salitre y guano a finales de la década de los setenta. Lo anterior conduce a lecturas contradictorias con respecto al alcance, significado y justificación del pacto secreto suscrito entre Bolivia y Perú, para quienes se justifica por el expansionismo territorial y económico chileno. Todo lo contrario, Chile se percibe a sí mismo como un enemigo y una amenaza injustificada, extensible también a las tensiones con Argentina, lo cual explica su necesidad vital de defenderse y protegerse militarmente ante potenciales enemigos.

En cualquier caso, no hay dudas, ni en los testimonios ni en la bibliografía consultada, que la victoria militar chilena era incuestionable, tanto por el fusil de retrocarga y otras innovaciones militares que le daban una importante ventaja en el combate cuerpo a cuerpo, como por su mayor disciplina castrense, la mayor cohesión de la relación cívico-militar, y por la misma capacidad de movilizar ciudadanos a la defensa de la causa nacional.

La causa marítima va a seguir coleando como la gran razón irresoluta de las relaciones geopolíticas entre Bolivia, Chile y Perú, pendiente de una solución tripartita, y más allá de la reciente decisión adoptada por $\mathrm{CIJ}$, lo cual no invita al optimismo, habida cuenta de que Chile resuelve la disputa invocando mirar al futuro y, por ende, entendiendo que este tipo de reclamo es tan anacrónico como nada factible.

A partir de ahí es fácil entender cómo se alimenta un relato nacional, presente en las escuelas, mucho más acentuado en los casos de Bolivia y Perú. Sin embargo, más allá de los llamados al futuro, a la integración, a la cooperación intergubernamental y al aliento de nuevas miradas, pareciera que aún son contadas las nuevas lecturas, más conciliadoras, sobre la Guerra del Pacífico. Puede que sin éstas resulte imposible abrazar nuevos senderos de un campo de estudio, hasta el momento, abonado por lecturas y miradas mayormente presentadas como irreconciliables.

Referencias

ABECÍA, V. Las relaciones internacionales en la historia de Bolivia. La Paz: Los Amigos del Libro, 1979

ARELLANO, J. C. "El pueblo de filibusteros y la raza de los malvados: discursos nacionalistas chilenos y peruanos durante la Guerra del Pacífico (1879-1884). Diálogo Andino, 48, 71-83, 2015. 
ARELlANO, J. C. "Discursos racistas en Chile y Perú durante la Guerra del Pacífico (18791884)”. Estudos Ibero-Americanos, 38(2), 239-264, 2012.

ARIÑO, A. "Ideologías, discursos y dominación”. Revista Española de Investigaciones Sociológicas, 79, 197-219, 1997.

BARZELAY, M. y CORTÁZAR, J. C. Una guía práctica para la elaboración de estudios de caso sobre buenas prácticas en gerencia social. Washington: INDES, 2004.

BLACK, J. Rethinking Military History. Nueva York: Routledge, 2004.

BONILLA, H. Guano y burguesía en el Perú. Lima: Instituto de Estudios Peruanos, 1974.

BONILLA, H. Un siglo a la deriva: Ensayos sobre el Perú, Bolivia y la guerra. Lima: Instituto de Estudios Peruanos, 1980.

EDELMAN, M. La construcción del espectáculo político. Buenos Aires: Manantial, 1991.

FARCAU, B. Chile, Peru, and Bolivia in the War of the Pacific, 1879-1884. Westport: Praeger Publishers, 2000

FERNÁNDEZ, E. et al. “Textos escolares y la guerra del pacífico: ¿Obstáculos o instrumentos para la integración de chilenos y peruanos?” Revista de Pedagogía, 38(102), 53-79, 2017.

FIGUEROA, C. “Geografías en disputa. La construcción del Chile territorial”. Revista 180, 141, $8-13,2011$

GEERTZ, C. La interpretación de las culturas. Barcelona: Gedisa, 1987.

GODOY, M. "Ha traído hasta nosotros desde territorio enemigo, el alud de la guerra”: Confiscación de maquinarias y apropiación de bienes culturales durante la ocupación de lima, 1881-1883”. Historia, 44(2), 287-327, 2011.

GODOY, M. "Los prolegómenos de una crisis episódica: El cantón de Taltal y la ley de impuesto a la producción salitrera, 1873-1883”. Historia, 49(2), 455-486, 2016.

IBARRA, P. "Peruanos y bolivianos en la sátira chilena de la Guerra del Pacífico (1879-1884)”. Historia y Comunicación Social, 21(1), 75-95, 2016.

KLAREN, P. “Los orígenes del Perú moderno, 1880-1930”. Bethell, L. (ed.). Historia de América Latina (vol. 10). Barcelona: Crítica, 1996.

KLEIN, H. Historia General de Bolivia. La Paz: Juventud, 1982.

KLEIN, H. “Bolivia desde la Guerra del Pacífico hasta la Guerra del Chaco, 1880-1932”. Bethell, L. (ed.). Historia de América Latina (vol. 10). Barcelona: Crítica, 1996.

KUUS, M. “Foreign Policy and Ethnography: A Skeptical Intervention”. Geopolitics, 18(1), 115$131,2013$.

LANZA, J. "El método narrativo para entenderla trayectoria y el funcionamiento de las políticas públicas locales”. Ciencia Política, 12(23), 175-203, 2017.

MCEVOY, C. “Chile en Perú: guerra y construcción estatal en Sudamérica, 1881-1884”. Revista de Indias, 236, 195-216, 2006.

MCEVOY, C. Armas de persuasión masiva: Retórica y ritual en la Guerra del Pacífico. Centro de Estudios Bicentenario, Santiago, 2010.

MCEVOY, C. Guerreros Civilizadores: Política, Sociedad y Cultura en Chile durante la Guerra del Pacífico. Santiago: Universidad Diego Portales, 2011.

MCEVOY, C. "Civilización, masculinidad y superioridad racial: una aproximación al discurso republicano chileno durante la Guerra del Pacífico (1879-1884). Revista Sociología Política, 20(42), 73-92, 2012

MORA, M. “La Casa Gibbs y el monopolio salitrero peruano: 1876-1878”. Historia, 41(1), 63-77, 2008.

OLGUín, P. "Fantasmas de rojo y azul. Los saqueos de las tropas chilenas en la guerra del Pacífico”. Anuario colombiano de historia, sociedad y cultura, 43(1), 263-293, 2016.

Parodi, D y Chaupis, J. Lo que decimos de ellos: La guerra del Pacífico en la historiografía y manuales escolares peruanos. Lima: Universidad de Lima, 2019.

PARODI, D. La Guerra del Pacífico en la historiografía y manuales escolares chilenos. Lima: PUCP, 2010

PROKKOLA, E. "Using Narrativity as Methodological Tool”. ACME: An International E-Journal for Critical Geographies, 13(3), 442-449, 2014. 
QUEREJAZU, R. Guano, salitre y sangre: Historia de la Guerra del Pacífico. La Paz: Los Amigos del Libro, 1978.

RÍOS, J. y CAIRO, H. "Los discursos sobre la participación política en el proceso de paz de Colombia”. Araucaria. Revista Iberoamericana de Filosofía, Política y Humanidades, 20(39), 317-339, 2018.

ROJAS, C. y SALAZAR, M. "La patria en escena: El teatro chileno en la guerra del pacífico". Historia, 48(1), 77-97, 2015.

ROJAS, F., ARAYA, A. y RAMÍREZ, D. "Tras los pasos de la muerte. Mortandad en Tacna durante la Guerra del Pacífico, 1879-1880”. Historia, 50(2), 399-441, 2017.

SATER, W. Chile and the War of the Pacific. Nebraska: University of Nebraska Press, 1986.

SATER, W. Andean Tragedy: Fighting the War of the Pacific, 1879-1884. Lincoln: University of Nebraska Press, 2007.

SICOTTE, R., VIZCARRA, C. y WANDSCHENEIDER, K. "The Fiscal Impact of the War of the Pacific". Cliometrica, 3, 97-121, 2009.

STOCKMEYER, V. "El ejército de Chile en vísperas de la Guerra del Pacífico: una visión de las tropas (1866-1879). Historia, 1, 135-155, 2016.

TÉLLEZ, E. Historia General de la frontera de Chile con Perú y Bolivia. Santiago: Universidad de Santiago de Chile, 1989.

VAN DIJK, T. "Discurso y dominación”. Grandes Conferencias en la Facultad de Ciencias Humanas, 4, 5-28, 2004.

VAN DIJK, T. "Ideología y análisis del discurso". Revista Utopía y Praxis Latinoamericana, 29, 9-36, 2005

ZEGARRA, L. "Reconstruction of export series for Peru before the Great -Depression". Journal of Iberian and Latin American Economic History. En prensa, 2018. 